\title{
On the Fictive Reading of German Steigen 'Climb, Rise': A Frame Account
}

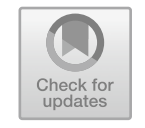

\author{
Thomas Gamerschlag and Wiebke Petersen
}

\begin{abstract}
Fictive motion, i.e., the figurative stative use of verbs of motion, has attracted much attention in cognitive linguistics as a paradigm case for how basic dynamic concepts are exploited figuratively in concept formation (Langacker 1986; Matsumoto 1996; Talmy 2000; Matlock 2004a, b inter alia). In this paper, we present a case study of the fictive motion reading of the German movement verb steigen "climb, rise' and explore how it can be related to the various dynamic readings of the verb. In our account of steigen, which builds on Gamerschlag, Geuder \& Petersen's (2014) analysis of the dynamic readings of the verb, we contrast the different readings in terms of frames, i.e., recursive attribute-value structures in the sense of Barsalou (1992) and Petersen (2007/2015).
\end{abstract}

Keywords Fictive motion - Verbs of motion - Stative reading of dynamic verbs • steigen/rise $\cdot$ Frame analysis

\section{Introduction}

In fictive motion, verbs of motion are applied to describe a stative scenario in which the subject referent usually is a stationary, non-moveable entity. In the most typical cases, the subject refers to some kind of pathlike entity such as a road or a line while the original theme, the moving participant of the literal use of the verb, remains unrealized. A German example of the fictive motion use of some verbs is given in (1) below. As can be seen, fictive motion uses serve to highlight spatial properties of the subject referent: laufen 'run' combines with the modifier quer 'diagonal' and a directional PP which specify the location of the scar and its orientation in relation to the cheek. Moreover, springen 'jump' plus PP identifies the eye as a region where the scar is interrupted, while landen 'land' locates the final part of the scar in the eyebrow when combined with the PP in (1).

T. Gamerschlag $(\bowtie) \cdot$ W. Petersen

Heinrich-Heine-Universität Düsseldorf, Düsseldorf, Germany

e-mail: gamer@phil.hhu.de 
(1) Eine [...] Narbe lief quer über seine eine Wange. Sie sprang über sein a scar ran diagonally across his one cheek it leapt over his

Auge und landete in seiner Augenbraue. ${ }^{1}$

eye and landed in his eyebrow

A scar ran diagonally across one of his cheeks, leaping over his eye and landing in one of his eyebrows.'

In German, both manner of motion verbs as well as directed motion verbs allow for fictive readings. In (1), laufen 'run' and springen 'leap/jump' are verbs encoding manner, whereas landen 'land' refers to a downward motion which ends up on some surface. Additional examples of fictive readings of path verbs are given below. For instance, in (2), the verbs überqueren 'cross' and abbiegen 'turn off (the road)' are applied to highlight properties of the course of the road.

(2) Die Straße überquert den Fluss und biegt dann in Richtung Flughafen ab. the road crosses the river and turns then in direction airport PARTICLE 'The road crosses the river and then turns in the direction of the airport.'

Likewise, steigen 'rise', which originally denotes a dynamic change in height of a moveable object, refers to an upward slope of the terrain in (3).

(3) Der Weg steigt [...] langsam auf eine Höhe von $4450 \mathrm{~m}^{2}$
the trail climbs $\quad$ slowly to a height of $4450 \mathrm{~m}$
'The trail climbs slowly to a height of 4450 meters.'

The verb steigen, variously translated as 'climb', 'rise' and also 'step', is highly polysemous. It exhibits a use as a manner of motion verb in addition to a purely directional reading and an "intensional" (figurative) use, as well as a fictive motion reading as in (3). We consider the meaning of steigen as a representative example of a complex array of different verb senses and the way they are systematically interrelated. These different senses will be illustrated in Sect. 3 after a concise overview of previous approaches to fictive motion in Sect. 2. In Sect. 4, we will give a short summary of Gamerschlag et al.'s (2014) frame approach to the dynamic readings of steigen. After a closer look at the fictive motion use of the verb in Sect. 5, we will present a frame analysis of this reading in Sect. 6. In Sect. 7 the fictive motion use of steigen is compared to the intensional use. Finally, in Sect. 8 we will indicate how the sketch of our frame analysis of fictive motion can be extended and elaborated on in various ways.

\footnotetext{
${ }^{1}$ Example taken from the novel Der fünfte Spieler by Blue Balliet, Aufbau Digital 2011.

${ }^{2}$ www.bhutan-travel.de/index.php/trekking-in-bhutan/mittelschwere-treks/18-trekking-in-bhutan/ 184-jhomolhari-trek (accessed 5 June 2019)
} 


\section{Previous Accounts of Fictive Motion}

Given the confinements of this paper, it is not possible to do justice to all the work that has been done in regard to fictive motion phenomena in the past decades. The recognition of fictive motion as such and its relevance to language, concept formation and cognitive processing is a merit of cognitive linguistics. The term 'fictive motion' goes back to work by Leonard Talmy, starting out from the 70's, developing over the following decades and resulting in insights such as the typology of fictive motion presented in Talmy (2000). Though alternatively referred to by terms such as 'abstract motion' (Langacker 1986) and 'subjective motion' (Matsumoto 1996), the phenomenon is characterized by a well-defined empirical base which also allows for cross-linguistic comparison. The central claim of cognitive linguists that fictive motion involves the mental simulation of movement or scanning along a path has been corroborated by psycholinguistic research which builds on results from various kinds of experiments. Matlock (2004b) and more recently Matlock and Bergmann (2014) and Hütte and Matlock (2016) give an excellent overview of experimental research on the phenomenon, including their own work. Different kinds of experiments such as narrative understanding tasks and studies based on drawing and eye movement provide evidence that fictive motion goes along with a conceptualizer simulating motion. Matlock (2004b) also shows how assuming mental simulation as part of the concept of fictive motion readings can account for a number of linguistic properties such as the spatial characteristics of the subject referent and the co-occurrence of temporal expressions. In spite of all their insights on the phenomenon, cognitive analyses usually refrain from a formal representation, thereby lacking a level of explicitness necessary for a deeper understanding of fictive motion. Instead, much of the discussion in the cognitive linguistics realm centers around the question of how fictive motion fits into accounts of metaphor and metonymy. For instance, Kövecses (2015) argues against an analysis of fictive motion in terms of conceptual metaphor, since an account of this type would involve an incomplete mapping, leaving components of the dynamic source, such as the moving entity, without a corresponding element in the static target. More recently, stative readings of dynamic verbs have attracted some attention in formal semantics. In his analysis of the stative uses of motion verbs, Gawron (2009) provides an elaborate account of spatial change as opposed to temporal change in which he focuses on so-called "spreading motion" referred to by extent verbs such as widen and cover. Following Gawron's ideas, Koontz-Garboden (2010) and Deo et al. (2013) propose accounts of stative uses of dynamic verbs in which the time scale/axis underlying the dynamic use is replaced by a spatial scale/axis. Although these time-to-space transfer analyses elegantly explain a number of properties of stative uses including the co-occurrence of various modifiers, they do not explicitly address fictive motion constructions of the type illustrated above. It is not clear, therefore, how these approaches would account for the range of modifiers that show up as a result of the dynamic origin of fictive motion. In the following sections, we will present a first sketch of a frame analysis of the fictive reading of steigen which deals with the range of co-occurring modifiers and the way they are linked to the dynamic source of fictive motion. 


\section{The Four Major Readings of Steigen 'Climb, Rise, Step'}

Due to its complex polysemy, the German verb steigen 'climb, rise, step' is particularly interesting in regard to the question of how the fictive motion use is embedded in the meaning array of a basically dynamic verb of motion. Gamerschlag et al. (2014:116) distinguish the four major uses illustrated in (4).

(4) steigen

a. as a verb of manner of motion

Die Ziegen steigen auf's Dach/vom Dach (herunter).

the goats climb onto.the roof from.the roof (down)

'The goats are climbing onto the roof / (down) from the roof.'

b. as a verb of directed motion

Der Ballon steigt höher und höher / *tiefer und tiefer.

the balloon climbs higher and higher deeper and deeper

'The balloon is climbing higher and higher / *deeper and deeper.'

c. as an intensional verb of change along a property scale

Die Temperatur steigt von 3 auf $10 \mathrm{Grad} \mathrm{/} \mathrm{*von} 3$ auf $10 \mathrm{Grad}$. the temperature rises from to degrees from to degrees 'The temperature is rising from 3 to 10 degrees / *from 10 to 3 degrees.'

d. as a static verb of "fictive motion"

Das Gelände steigt von 750 auf 761 Meter $[\ldots]^{3 /} \quad$ *von 761 auf 750 Meter. the terrain climbs from to meter from to meter

'The terrain climbs from 750 to 761 meters / 761 to 750 meters.'

The readings illustrated in (4a) and (b) are literal dynamic uses of the verb which refer to movement in space. They can be differentiated due to a couple of asymmetries. First, steigen as a verb of manner of motion (henceforth steigen $_{m m}$ ) requires the use of limbs for the kind of motion referred to. Therefore, only animate subject referents with a suitable anatomy are permitted, such as Ziegen 'goats' in (4a). It is important to note that steigen $_{m m}$ is not confined in regard to the direction of motion. As can be seen in (4a), PPs specifying upward as well as downward motion are admissible. Directional steigen (henceforth steigen $_{\text {dir }}$ ) as in (4b) does not make reference to a particular manner of using one's limbs. By consequence, the subject referents of steigen dir $_{\text {can }}$ refer to freely suspended entities such as Ballon 'balloon' in (4b). However, steigen dir $_{\text {can only }}$ denote upward movement as shown by the non-admissibility of a modifier specifying a downward path. This asymmetry in regard to admissible directional complements correlates with their omissibility: While directional PPs can be left out with steigen $_{\text {dir }}$ they cannot be omitted with steigen sm $_{\text {. }}$

The example in (4c) illustrates a figurative use of steigen which abstracts away from spatial motion while referring to abstract "motion" along a scale, such as

\footnotetext{
${ }^{3}$ https://www.suedkurier.de/region/bodenseekreis-oberschwaben/heiligenberg/Neues-Wohnenund-Arbeiten-in-Heiligenberg;art372476,8460587 (accessed 5 June 2019)
} 
the temperature scale introduced by the subject. Following the formal analyses by Montague (1973) and Löbner $(1979,1981)$ among others, we will refer to this use as 'intensional steigen' (henceforth steigen $_{\text {ins }}$ ). Characteristically, this use involves a total change of the subject referent over time, as opposed to the partial change of the subject referent in the literal readings in the first two examples in (4), in which the subject referent only changes with respect to a single dimension, namely its spatial location. Like steigen dir $_{\text {steigen }}$ ins can only express an increase along the respective scale but never a decrease. In spite of its abstractness, steigen $n_{\text {ins }}$ refers to a true dynamic change within a particular value space. By consequence, it can be grouped together with the two literal meanings given in (4).

In contrast, the fictive motion use of steigen (henceforth steigen $_{\text {fict }}$ ) does not involve motion interpreted as a dynamic change during the course of the event. Instead, it refers to a stative spatial scenario in which the subject referent is a stationary, usually not moveable entity characterized as having some gain in height. For instance, in (4d) it is specified that the slope of the referent of Gelände 'terrain' has a positive difference in height of 500 meters between some non-realized starting and end point. As with steigen dir $_{\text {and }}$ steigen $_{\text {ins }}$, steigen $_{\text {fict }}$ (i) allows for an absolute use and (ii) can only refer to upward 'fictive' motion while downward motion is excluded, as shown by the non-admissibility of a negative height difference. In this regard steigen parallels English climb whose fictive motion use is also restricted to a positive difference in height, thereby relating it more closely to the dynamic directional use of climb while setting it apart from the manner reading (cf. Fillmore 1982; Jackendoff 1985; Matsumoto 1996).

Note that many speakers seem to have some preference to use steigen in its fictive use with a verbal particle such as an 'up(wards)' rather than choosing the particleless variant, which is often judged as less felicitous or incomplete. However, the argument that steigen $_{\text {fict }}$ is restricted to a positive gain in height can only be made on the base of the particleless variant since in the case of the complex verb ansteigen 'ascend, move upwards' one may argue that the upward direction is solely contributed by the particle, while the verb itself could be analyzed as being indifferent with regard to the direction of the path. Likewise, the frame account proposed by Gamerschlag et al. (2014) covers only the (non-fictive) simplex uses of steigen. Since our analysis of steigen $_{\text {fict }}$ directly builds on their approach, we will focus on the fictive use of steigen without the particle. Nonetheless, a complete understanding of steigen $n_{\text {fict }}$ requires a discussion of its relation to the fictive readings of steigen plus particle which, however, is beyond the limits of this paper. ${ }^{4}$ In order to not rely solely on introspection, we have drawn the examples of steigen $_{\text {fict }}$ mainly from internet sources, being well aware of the unreliability of data of this sort.

In the following sections, we will propose an analysis of steigen $_{\text {fict }}$ in which its meaning is derived from that of steigen $_{\text {dir }}$, due to similar semantic restrictions.

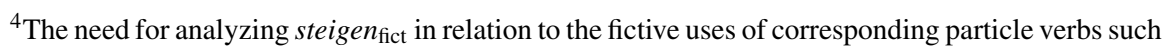
as ansteigen and aufsteigen 'ascend/move upwards' was pointed out to us by one of the reviewers. The same reviewer also stated that according to his/her grammaticality judgements the fictive use of simplex steigen is in principle unproblematic.
} 
Starting from the frame representations of the two literal uses in (4), we will show that the frames of both steigen $n_{\text {fict }}$ as well as steigen $_{\text {ins }}$ result from structural operations on the frame of steigen $_{\text {dir }}$ which are necessary to accommodate the frame of the subject referent. Before going into the details of our analysis, we will first give a short introduction into the frame model we adopt.

\section{Frame Analysis of Dynamic Steigen: Manner and Directional Reading}

\subsection{Frames for Objects}

The participants of an event denoted by a verb can be many different kinds of different objects. Usually, these objects are the referents of nominal concepts introduced by noun phrases. Following Barsalou's (1992) idea that conceptual knowledge is represented by means of frames, which provide an explicit, variable-free, and cognitively plausible representation format, we assume that nominal concepts are best captured by frame representations. More precisely, we build on Löbner's (2011) theory of nominal concept types and Petersen's (2007/2015) formalization of frames according to which frames are defined as recursive attribute-value structures with the attributes corresponding to mathematical functions. For illustration, the graph representation of the object concept 'building with brick walls and gabled tiled roof' is given in Fig. 1 below.

The central node specifies the referent of the frame, in this case a particular type of building. The referent is characterized by the attributes branching off the central node: The mereological attributes ROOF, WALLS, and BASE map the referent to particular parts of it. In addition, the value of the attribute PURPOSE points to the function of the building to serve as some kind of shelter. Frames are characterized by their recursive potential, allowing for zooming into the nodes by expanding them into additional attribute-value pairs. For instance, the value of ROOF has the two attributes SHAPE and MATERIAL, each of which comes with particular values. Note that the frame graph in Fig. 1 is kept reasonably simple for the sake of illustration. In principle, frame representations can be unlimitedly detailed by specifying additional attributes and their possibly complex values.

In spite of their flexibility, the range of frames is not arbitrary in the model we adopt. Rather, frames are determined by a type signature that specifies admissible attributes and the type of values they can take. Type signatures model conceptual knowledge and express all kinds of learned constraints such as hierarchical relations, the set of attributes which are adequate for frames of a given type, as well as value restrictions and value dependencies (cf. Petersen 2007/2015 for details). 


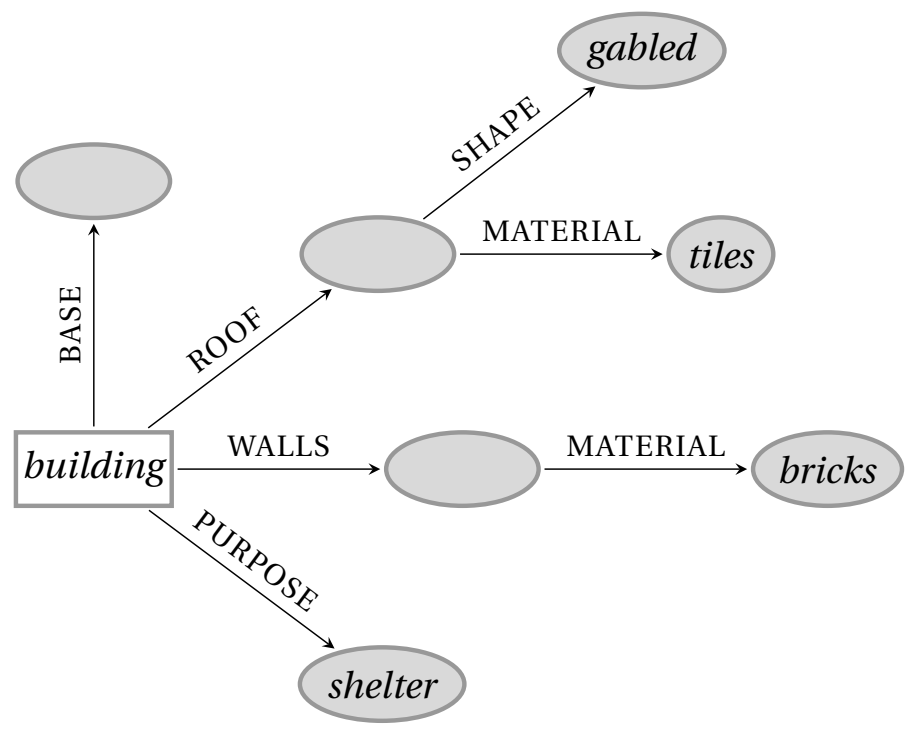

Fig. 1 Frame representation of 'building with brick walls and gabled tiled roof'

\subsection{Steigen $_{m m}$}

When it comes to the frames of verbs, things get more complicated since time and change come into play. Following Naumann's (2013) model of verb frames, a verbal concept can be represented by an overall event frame which represents the global properties of this event. This frame is static in the sense that it does not change during the event. Gamerschlag et al. (2014) assume the static event frame (SEF) for steigen $_{m m}$ in Fig. 2 below.

The frame representation in the figure above expresses the relations of the objects involved in an event of that sort: steigen $_{m m}$ has a theme and a path argument which are satisfied by syntactic complements. In the representation, this is indicated by open argument slots marked by square nodes. Moreover, steigen $_{m m}$ is executed in

Fig. 2 Static event frame of steigen $_{m m}$

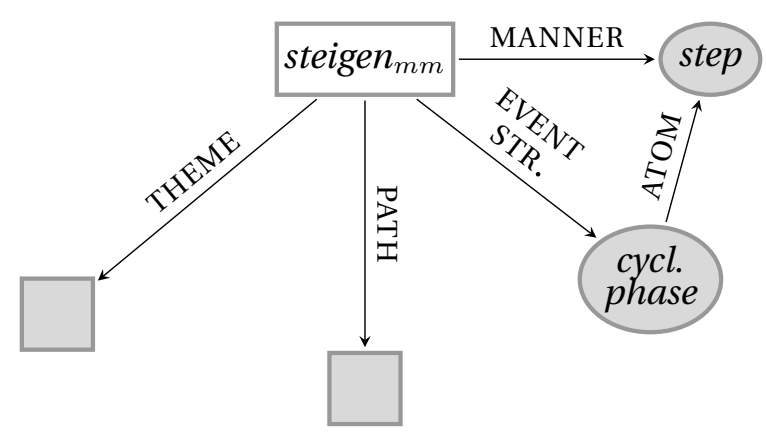


a particular manner characterized by step(s) which are the atoms of its internally cyclic event structure. Note that although a typical steigen $_{m m}$-event consists of a continuous repetition of steps, it can also be instantiated by a single step, as pointed out by Geuder and Weisgerber (2008).

The static event frame is not satisfactory as the sole representation of a dynamic event denoted by steigen $_{m m}$. In order to temporalize frames, they need to be related more explicitly to event structure. To this end, Naumann (2013) assumes a threelevel model of event representation, which can only be sketched here for reasons of space (see Naumann 2013 and Gamerschlag et al. 2014 for details). ${ }^{5}$ First, in addition to the level of static event frames, a level of event decomposition (ED) is required which refers to the temporal structure of an event. In the case of steigen $_{m m}$, event decomposition results in a sequence of atomic step-subevents e $1, \mathrm{e} 2, \ldots$ as shown in the middle of Fig. 3. These subevents are linked to the relevant parts of the static event frame by a zoom function $\mathrm{Z}$ such that each atom consists of a single step executed by the theme. As a third level, the situation frame-level (SF) at the bottom of Fig. 3 captures the event-related changes of the participants during the course of the event. In the case of an event structure consisting of atoms, the SF-level provides snapshots of the entity's state at the boundary of each atom. For steigen ${ }_{m m}$ this means that the change of position of the moving entity (i.e., the subject referent) after each step is specified at this level. Again, the zoom function works as a linking device between the two levels by mapping boundary events to situation frames.

Given the model introduced above, Gamerschlag et al. (2014) assume the frame of steigen $_{m m}$ in Fig. 4, which results from expanding the manner component into a detailed subframe. This subframe provides information on the force constellation involved by characterizing it as a noticeable, upwards-directed force that is exerted by legs against a solid antagonist.

Note that the frame in the figure above is not static since it reflects the changing location of the subject referent captured at the SF level in Fig. 3. Rather, this frame is some kind of condensed representation that also contains dynamic aspects of the three-level representation outlined above. This is achieved technically by the dynamic attribute TRACE which links the POSITION of the THEME of steigen $_{m m}$ to its PATH specification. More precisely, TRACE is an attribute that is projected into this frame from the event decomposition frame and maps the changing POSITION of the THEME value to the record of its trace in the time span of the event. Because of their special status, dynamic attributes are indicated by broken lines in the frame graphs.

\footnotetext{
${ }^{5}$ Löbner (2017) proposes an alternative account for capturing change of state verbs in terms of Barsalou frames using first-order comparators. Due to lack of space we cannot discuss his approach and how it can be adopted for the analysis of fictive motion by mapping a change in time onto a change in space.
} 


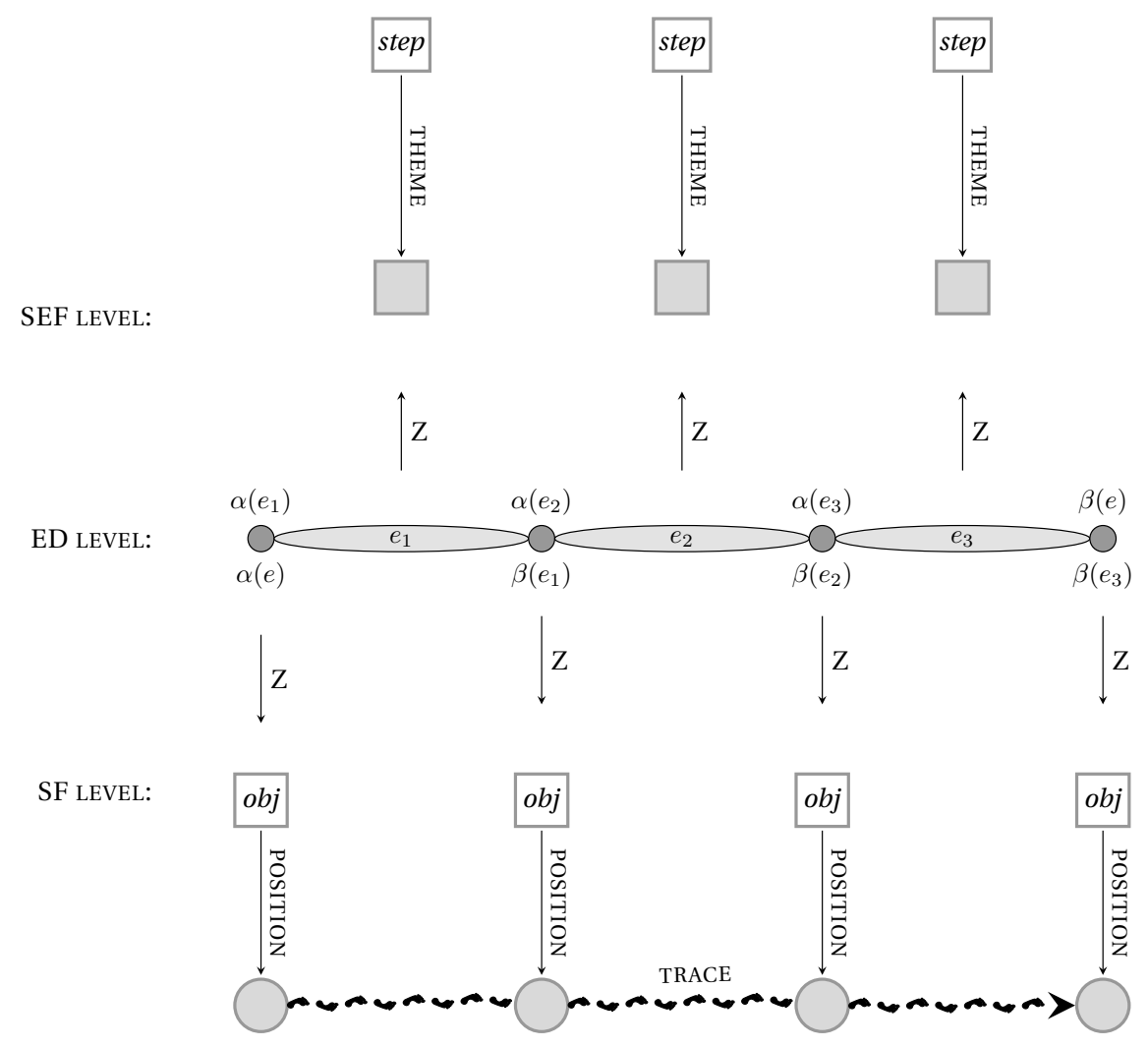

Fig. 3 Event structure of steigen $_{m m}$

\subsection{Steigen $_{\mathrm{dir}}$}

As outlined in Sect. 3, steigen $_{\text {dir }}$ differs from steigen ${ }_{m m}$ in that it refers to the movement of a freely suspended object without requiring the use of limbs. At the same time, steigen $_{\text {dir }}$ is more restricted than steigen $_{m m}$ since it can only refer to upward movement. Figure 5 shows the condensed event frame of steigen $_{\text {dir }}$.

As can be seen, the rich manner component of the frame of steigen $_{m m}$ is not

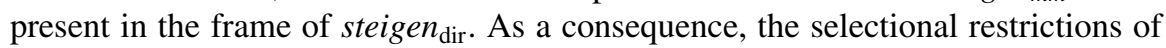
steigen $_{m m}$ do not hold for steigen $_{\mathrm{dir}}$. Moreover, due to the absence of the step-atoms of the manner component, the event structure is not cyclic anymore but can rather be characterized as a continuous phase. As a further contrast to the frame for steigen ${ }_{m m}$, the values of PATH are confined to expressing upward movement. However, apart from the value restriction of the PATH-attribute, the frame component referring to the theme's changing position and the formation of the path by means of the TRACEfunction is shared by the condensed frames of both readings. In our analysis, we will show how the frame of steigen $_{\text {fict }}$ can be derived from the frame of steigen $_{\text {dir }}$. 


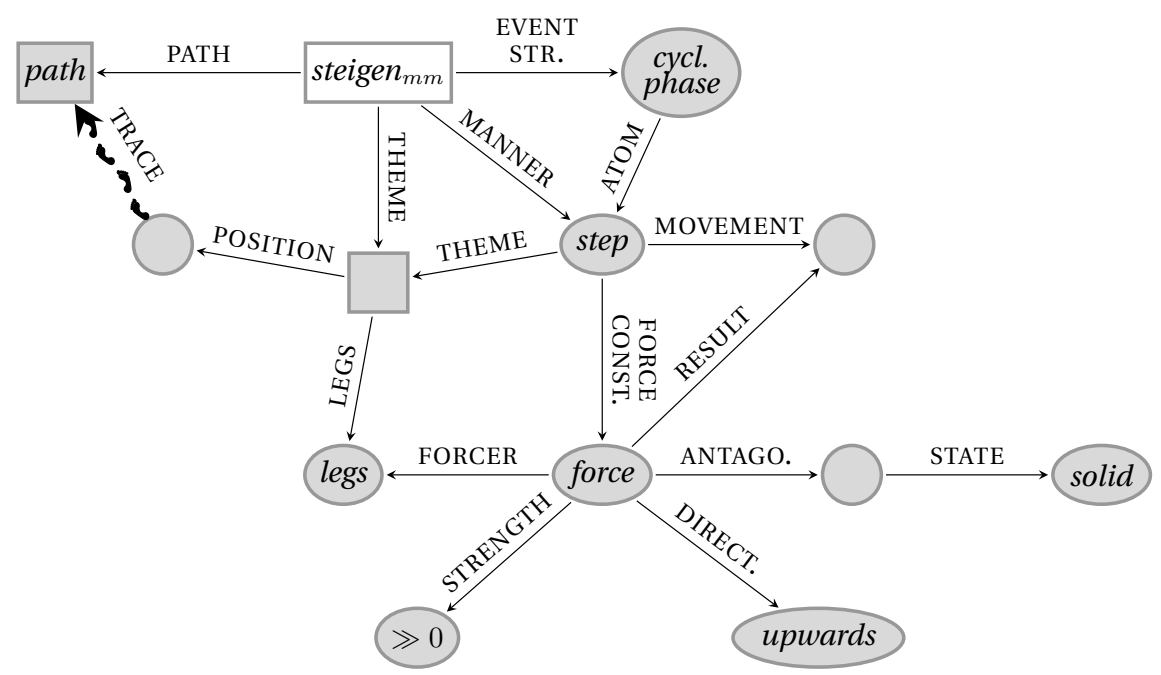

Fig. 4 Condensed event frame of steigen $_{m m}$

Fig. 5 Condensed event frame of steigen $_{\text {dir }}$

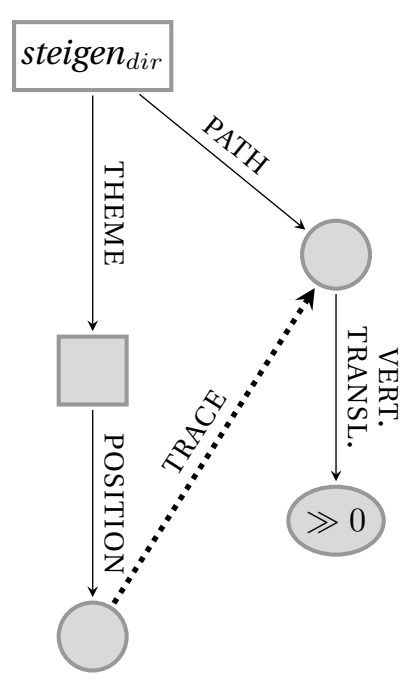

\section{Steigen $_{\text {fict }}$ : Admissible Modifiers and Subject Referents}

Before outlining our account of steigen $_{\text {fict }}$ in Sect. 6, we will first have a short look at the range of admissible modifiers and subject referents found with this reading. In addition to permitting adverbial modifiers referring to upward motion, steigen $_{\text {fict }}$ 
can combine with adverbs specifying properties such as the slope and the shape of a path, as shown by the examples in (5) and (6).

(5) Der Pfad steigt steil/sanft auf den Gipfel. the trail climbs steeply/gently to the summit. 'The trail climbs steeply/gently to the summit.'

(6) Die neu asphaltierte Straße [...] steigt kurvenreich auf eine the newly asphalted road climbs in.serpentines to a Art Hochplateau. ${ }^{6}$

kind.of plateau

'The newly asphalted road winds upwards (lit.: climbs in serpentines) to some kind of plateau.'

Moreover, adverbs such as schnell 'quickly' and langsam 'slowly' which are normally associated with temporal properties of dynamic concepts naturally occur with the fictive use, as shown in (7) below. In addition, even modifiers such as mühsam 'strenuously' and gemütlich 'comfortably', which specify the way a human mover would experience real motion, are admissible.

(7) Der Weg steigt schnell / langsam / mühsam / gemütlich auf den Gipfel. the trail climbs quickly/slowly/strenuously/comfortably to the summit 'The trail climbs quickly / slowly / strenuously /comfortably to the summit.'

Another aspect relevant for the understanding of the fictive motion use is the range of admissible subject referents illustrated by the examples in (8). As can be seen, subject referents are not confined to traversable entities such as 'way' and 'road' in German: In (8a) and (b) the referents of Arteria 'artery' and Rohr 'pipe' are not traversable by humans. However, they still qualify as pathlike entities accessible for mental scanning. Moreover, in German the subject referents need not even be pathlike, as illustrated by (4d) in which a subject such as Gelände 'terrain' refers to a twodimensional space. In our analysis, we will argue that subject referents of this type are licensed because they can be conceived of as embedding the path along which fictive motion can proceed. Likewise, the subject Wald 'forest' in (8c) can be interpreted as a two-dimensional entity referring to a specific area or region. Moreover, as shown by the examples in (8d) and (e), even subjects denoting three-dimensional entities are admissible if they provide prominent object sides that restrain possible paths of fictive motion. In these examples it is the (vertical) surface of the mountains and the skyscraper which contains the relevant path. Note that three-dimensional objects of the type illustrated in (8d) and (e) need to have a prominent vertical axis and a

${ }^{6}$ http://doczz.net/doc/301001/--hilti-foundation (accessed 5 June 2019) 
considerable height ruling out e.g. small objects such as bottles and candles which prototypically have a prominent vertical but are only of small height. ${ }^{7}$

\section{a. Die Arteria carotis externa steigt senkrecht nach oben. ${ }^{8}$} the arteria carotis externa rises vertically upwards 'The arteria carotis externa rises vertically upwards.'

b. Das Rohrsteigt senkrecht durch das Dach. ${ }^{9}$ the pipe rises vertically through the roof 'The pipe rises vertically through the roof.'

c. Der Wald steigt $[\ldots]$ bis auf 1 ' $870 \mathrm{~m}$ ü[ber] M[eeresspiegel $]^{10}$ the forest rises up to $1,870 \mathrm{~m}$ above sea level 'The forest rises to 1,870 meters above sea level.'

d. Das Gebirge steigt in unmittelbarer Nähe der Küste [...]. the mountainsrises in immediate proximity of.the coast auf 4000 Höhenmeter. ${ }^{11}$

to 4000 meters.in.height

'The mountains rise up to 4000 meters in height close to the coast.'

e. Das Hochhaus steigt siebzig Meter in die Höhe [...]. ${ }^{12}$

the skyscraperises 70 meters upwards

'The skyscraper rises 70 meters into the air.'

As already pointed out by Matsumoto (1996), the availability of non-traversable subject referents is language-dependent. For instance, while English and German are fairly liberal with respect to non-traversable subject referents, according to Matsumoto Japanese is more restricted, excluding subjects referring to walls and fences while allowing for wires and borders to appear as subject referents in fictive motion constructions. However, as observed by Matlock (2004a), even languages such as English and German are sensitive to the property of being traversable.

\footnotetext{
${ }^{7}$ One reviewer points out that s/he cannot accept three-dimensional subject referents with steigen $_{\text {fict }}$ while subjects denoting some kind of path or plane are fine. We agree with the reviewer that subject referents of the latter nature are prototypically found with this reading whereas subjects denoting entities of the former kind are more at the periphery of this use and may also vary with respect to native speakers' judgements. However, instances of steigen $_{\text {fict }}$ plus three-dimensional subject referents, whose grammaticality is also in line with our own judgements, need to be taken into account in a full-fledged analysis of this reading of steigen. Due to the lack of space and empirical data, we present some tentative frame account of this subtype of steigen $_{\text {fict }}$ in Sect. 6 but will refrain from elaborating on it apart from this sketch.

${ }^{8}$ Example taken from I. Bergstrand et al. (eds.) 1964. Röntgendiagnostik des Herzens und der Gefäße, p. 655. Berlin: Springer.

${ }^{9}$ Example taken from Allgemeine medizinische Zeitung mit Berücksichtigung des Neuesten und Interessantesten der allgemeinen Naturkunde, issue of year 1835, p. 1507. Brockhaus.

${ }^{10} \mathrm{https}: / /$ www.ur.ch/_docn/35377/22.pdf (accessed 5 June 2019)

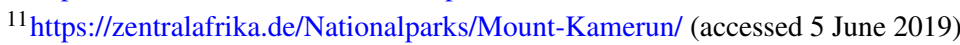

${ }^{12}$ Example taken from Hochparterre: Zeitschrift für Architektur und Design, vol. 27 (2014), p. 14.
} 
According to Matlock (2004a:231f) only "paths ordinarily associated with motion" allow for "information about the way the mover moved, for instance, quickly, slowly, erratically, effortfully [...]." Matlock (2004a:231f) illustrates this observation with the following contrast.
(9) a. The highway crawls through the city.
b. ??The underground cable crawls from Capitola to Aptos.

The construction in (9a) is felicitous because the subject refers to an entity which was constructed precisely for traveling and therefore is compatible with the particular manner of motion expressed by crawl, i.e. progressing slowly and laboriously. In contrast, the example in (9b) is ruled out because a human experiencer cannot be conceptualized as moving on an underground cable in this manner. Likewise, the use of climb as a translation of steigen $n_{\text {fict }}$ is only felicitous in cases of traversable subject referents since climbing implies the use of hands/feet whereas rise, which does not contain manner information of this kind, can be applied in combination with non-travellable subject referents.

Matlock's constraint is not confined to manner information expressed by the verb. Analogously, some external modifiers yield awkward results if they co-occur with subjects associated with non-traversable paths. As shown in (8b) (repeated as (10)) a non-traversable subject referent such as Rohr 'pipe' allows for modifiers such as senkrecht 'vertical' which specify the slope of the path. However, modifiers such as schnell 'quickly' and mühsam 'strenuously', which relate to a human moving along a travellable path, are excluded.

\section{(10) Das Rohr steigt senkrecht/??schnell/??mühsam durch das Dach. the pipe rises vertically/quickly/strenuously through the roof 'The pipe rises vertically /??quickly/??strenuously through the roof.'}

Obviously, the awkward combinations in (10) are ruled out because of some kind of clash between a non-traversable path denoted by the subject and the concept of a human moving along a path suitable for motion evoked by the context.

Given the range of modifiers and subject referents in the examples above, it becomes evident that a proper treatment of instances of fictive motion requires detailed access to properties of the subject referent. In the following section, we will show that the flexibility of frame representations allows for explicit reference to the relevant properties. In particular, we will address the contrastive array of admissible modifiers in dependence of the travellable/non-travellable distinction.

\section{Frame Analysis of Steigen}

For an approach to the fictive reading of steigen, we begin with the example in (11), which is a simplified version of the sentence in (3). 
(11) Der Weg steigt [...] auf eine Höhe von $4450 \mathrm{~m}$. the trail climbs to a height of $4450 \mathrm{~m}$

'The trail climbs to a height of 4450 meters.'

Given the fact that steigen $_{\text {fict }}$ is restricted to upward "movement" just as steigen dir $_{\text {, }}$ it is plausible to assume that the meaning of steigen $_{\text {fict }}$ is more closely related to steigen $_{\text {dir }}$ than to steigen $_{\mathrm{mm}}$. Starting from this observation, our idea goes as follows: If the subject refers to a stationary, non-moveable entity, the literal interpretations of steigen are both blocked due to a violation of sortal restrictions with respect to the subject referent. However, in spite of this, the subject referent of steigen $_{\text {fict }}$ can be accommodated by associating it with some suitable part of the existing frames of the literal readings of steigen. The value of the PATH-attribute in the frames for both of the literal readings is an entity that can be conceptualized as being embedded in the referent of the subject of steigen $_{\text {fict }}$. In this regard, both literal readings are appropriate for incorporating the stationary subject referent. However, the frame of steigen $_{\mathrm{dir}}$ is more suited to accommodate the new subject referent since it (a) is more explicit by specifying a path with an upward direction and (b) involves a minor loss of original meaning compared to steigen $_{m m}$, which would go along with the deactivation of manner information when combined with a non-appropriate stationary subject referent. Based on these considerations, we assume the frame in Fig. 6 as a representation of the example given in (11) above:

Fig. 6 Frame representation of Der Weg steigt auf eine Höhe von $4450 \mathrm{~m}$. 'The trail climbs to a height of $4450 \mathrm{~m} . '$

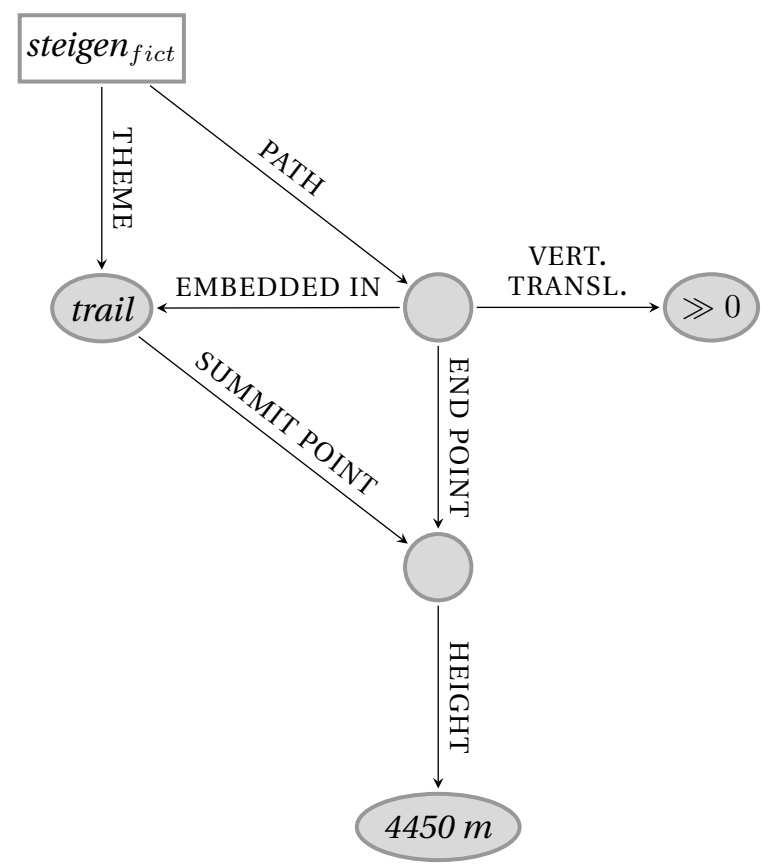


This frame is derived from that of steigen $_{\text {dir }}$ in the following way: First, the stationary subject referent is accommodated in the frame as a new THEME in which the path is embedded. A THEME suitable for that is, for instance, pathlike itself or exhibits a prominent surface that can accommodate a rising path. Second, the original THEME (i.e. the mover) is blocked from being realized which results in deactivation of the meaning components related to actual movement and, consequently, in arriving at the stativized interpretation characteristic of steigen $_{\text {fict }}$. Due to the value restriction

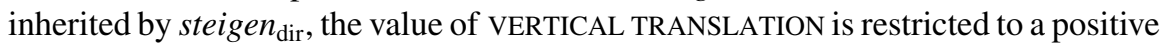
value. By consequence, the path can only be conceptualized as having an upward orientation. In addition, spatial modifiers such as auf $4450 \mathrm{~m}$ Höhe 'to a height of 4450 meters' further restrict the path value by activating additional attributes such as HEIGHT of ENDPOINT. Note that the value of ENDPOINT is shared with the attribute SUMMIT POINT of the theme. By consequence, the HEIGHT of the SUMMIT POINT is identified with the HEIGHT of the ENDPOINT of the path. Furthermore, it is important to note that the frame thus specifies a property of the theme, which is at the same time restricted by a property of the path. Next consider the example in (12), which is a simplification of the one given in (6).

\section{(12) Die asphaltierte Straße steigt kurvenreich auf ein Hochplateau. the asphalted road climbsin.serpentines to a plateau 'The asphalted road winds upwards (lit.: climbs in serpentines) to a plateau.'}

As shown in the representation of the sentence in Fig. 7, the modifier kurvenreich 'winding/in serpentines' evokes the PATH attribute SHAPE for which it highlights a particular value. This attribute is a direct attribute of the path object but its value is again shared with the SHAPE attribute of the theme. As in the preceding example, this ensures that some property of the theme is specified by the construction. As a general rule, we assume that an adverbial modifier of steigen $_{\text {fict }}$ is admissible if it

Fig. 7 Frame representation of Die asphaltierte Straße steigt kurvenreich auf ein Hochplateau. 'The asphalted road winds upwards (lit.: climbs in serpentines) to a plateau'

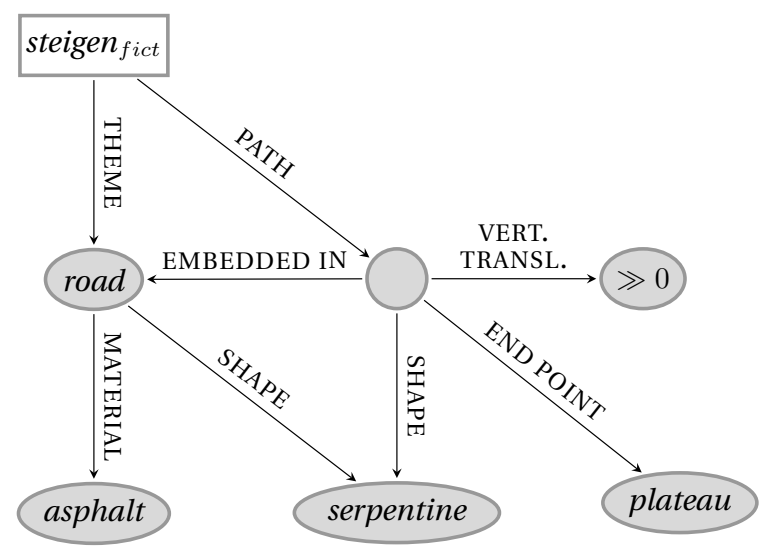


Fig. 8 Frame representation of Das Hochhaus steigt siebzig Meter in die Höhe. 'The skyscraper rises 70 meters into the air.'

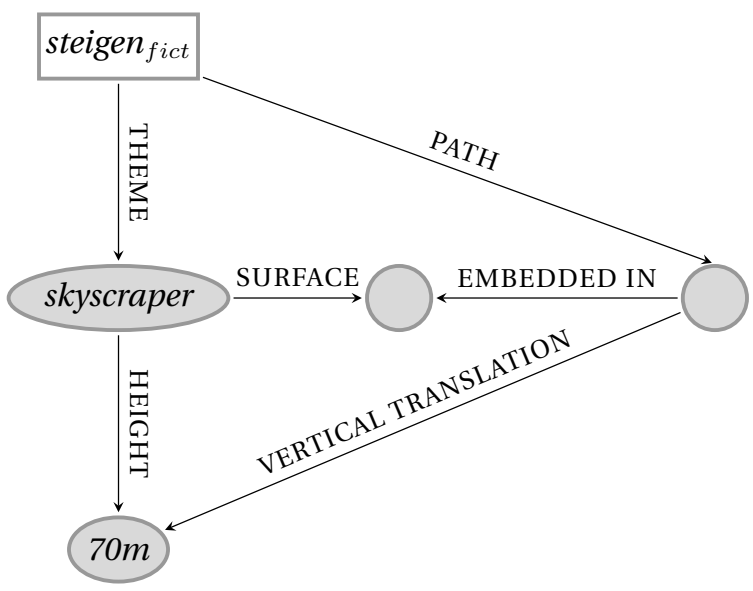

explicates a value of an attribute of the theme that is restricted by some property of the path. ${ }^{13}$

The example repeated in (13) exhibits a non-pathlike, three-dimensional subject referent.

(13) Das Hochhaus steigt siebzig Meter in die Höhe [...].

the skyscraper rises 70 meters upwards

'The skyscraper rises 70 meters into the air.'

Again, as shown in Fig. 8, the subject referent is accommodated in the frame via the EMBEDDED IN-attribute. More precisely, for three-dimensional entities such as a skyscraper, we assume that the path is embedded in their SURFACE, since it is this part which is accessible for visual scanning. In addition, (13) is interpreted in such a way that the VERTICAL TRANSLATION of the path and the HEIGHT of the skyscraper share the same value.

The use of steigen $_{\text {fict }}$ with non-pathlike subject referents of the type illustrated above appears to be highly restricted, requiring entities with a long and very prominent vertical axis. A better understanding of this combination requires further research that goes beyond the scope of this paper. Therefore, we consider the representation given in Fig. 8 to be only a first approximation of an analysis.

So far, the constraint that the adverbial modifier has to be restricted by some property of the path could be captured in the frame representation by means of value sharing between an attribute of the path and an attribute of the theme. However, if one considers the whole array of admissible modifiers such as the adverb langsam 'slowly' in (3) repeated in (14) below, it becomes evident that not each instance of steigen $_{\text {fict }}$ can be dealt with in this way.

\footnotetext{
${ }^{13}$ Similar restrictions on fictive motion expressions have already been proposed by Matsumoto (1996:194).
} 
(14) Der Weg steigt [...] langsam auf eine Höhe von $4450 \mathrm{~m}$. the trail climbs slowly to a height of $4450 \mathrm{~m}$ 'The trail climbs slowly to a height of 4450 meters.'

As argued above, modifiers related to real motion are only licensed if the subject referent provides a traversable path. We assume that this crucial property can be captured by means of an AFFORDANCE attribute understood in the original sense coined by Gibson $(1977,1979)$ as denoting "action possibilities provided to the actor by the environment (Kaptelinin 2013)." In the case of a subject referent suited for human travel we refer to the relevant attribute as TRAVEL AFFORDANCE as shown in Fig. 9. The value of TRAVEL AFFORDANCE is complex and licenses travel-related attributes such as VELOCITY, DURATION, DIFFICULTY, and EXPERIENCE. Moreover, it exhibits a PATH-attribute which shares its value with the PATH-attribute of the rootnode. By consequence, the value of TRAVEL AFFORDANCE varies depending on the particular instantiation of the value of PATH.

As mentioned earlier in this paper, experimental research has convincingly shown that the fictive motion uses of verbs come along with some kind of simulation of actual motion. Since the AFFORDANCE component is a representation of "action

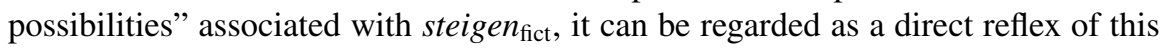

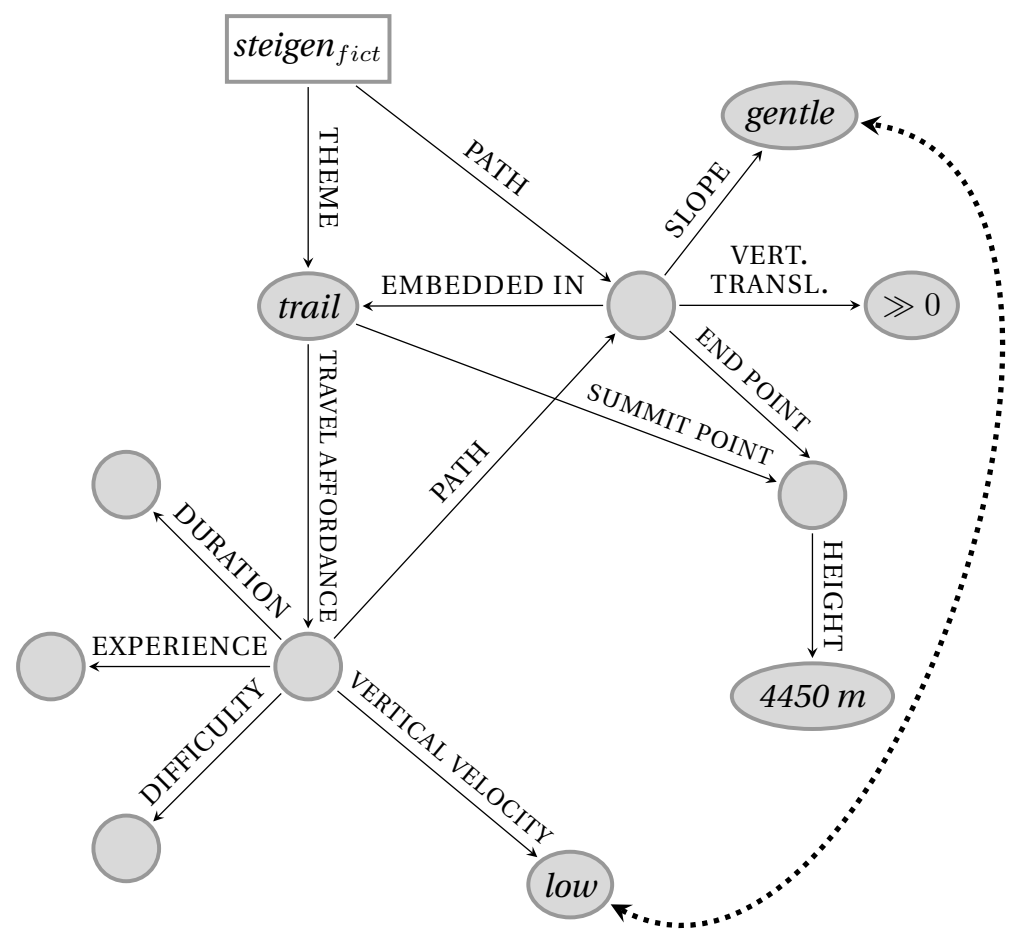

Fig. 9 Frame representation of Der Weg steigt langsam auf eine Höhe von $4450 \mathrm{~m}$. 'The trail climbs slowly to a height of $4450 \mathrm{~m}$ ' 
kind of simulation with the value of the PATH attribute of TRAVEL AFFORDANCE corresponding to the path that comes about as a result of mental scanning.

For a temporal modifier such as langsam 'slowly' in (14), we assume that it can be integrated into the frame representation as part of the affordance component as a low value of the attribute VERTICAL VELOCITY, which refers to the speed with which the height of a mover changes. This attribute-value pair is typically correlated with a gentle SLOPE, which is an attribute of PATH.

This correlation between the values of VERTICAL VELOCITY and SLOPE is given only for some average travel velocity of the mover which is contextually specified. Of course, one can also think of a high VERTICAL VELOCITY and a gentle SLOPE or a low VERTICAL VELOCITY and a steep SLOPE. However, this presupposes travel velocities above or below some contextually specified standard for travel velocity. ${ }^{14}$

As a general rule for the admissibility of a modifier of steigen $n_{\text {fict }}$ in terms of frames, we assume the following.

(15) A modifier of steigen $_{\text {fict }}$ is admissible iff it restricts the value of the PATH attribute by either specifying a value of an attribute of the PATH node which is shared with an attribute of the THEME node or by specifying the value of an attribute of the TRAVEL AFFORDANCE of the THEME node. Since the value of the PATH attribute is functionally dependent on the value of the TRAVEL AFFORDANCE attribute, a restriction of the latter by the specification of one of its attribute values implies a restriction of the former. This dependency often leads to a value correlation between an attribute of the PATH node and an attribute of the TRAVEL AFFORDANCE node.

In addition to adverbs specifying velocity, the rule in (15) also allows for experiencer related modifiers such as mühsam 'strenuously' and gemütlich 'comfortably' as in the example repeated below.
Der Weg steigt schnell/langsam / mühsam / gemütlich
auf den Gipfel.
the trail climbs quickly/slowly/strenuously/comfortably to the summit
'The trail climbs quickly / slowly / strenuously /comfortably to the summit.'

Modifiers of this type can be represented as values of the EXPERIENCE attribute of the TRAVEL AFFORDANCE node. As in the case of adverbs specifying values of VELOCITY, they are licensed because they can be interpreted as restricting the path. For instance, an adverb such as mühsam 'strenuously' can be conceived as being related to a steep SLOPE or a particularly meandering, non-linear SHAPE of the path. The way how the specification of the value of an attribute of travel affordance restricts the path also

\footnotetext{
${ }^{14}$ The "gentleness of the slope"/"a slow increase of elevation" as path properties being directly related to time adverbs such as slowly and likewise Japanese yukkuri 'slowly' has already been observed by Matsumoto (1996:202) with respect to fictive motion. We are grateful to one of the reviewers for pointing out to us that the alleged relation between velocity and slope does not necessarily have to hold (from a purely physical perspective). However, in our analysis we will keep with the prototypical relation between low velocity/gentle slope and high velocity/steep slope in accordance with observations such as the one made by Matsumoto.
} 
seems to be influenced to some degree by the context. We leave it open here how the interaction between attribute-value pairs of the PATH and TRAVEL AFFORDANCE nodes can be captured in a formally adequate way.

As the attribute TRAVEL AFFORDANCE is naturally restricted to appear with entities which allow for travel, non-traversable referents do not come with this attribute. By consequence, modifiers such as schnell 'quickly' and langsam 'slowly', which specify a value of an attribute of TRAVEL AFFORDANCE, are excluded if steigen $_{\text {fict }}$ combines with a subject referent not suitable for human travel. As a result, the set of admissible modifiers found with non-travellable subject referents is considerably smaller in comparison to the array of modifiers attested in combination with travellable subject referents.

\section{$7 \quad$ Steigen $_{\text {ins }}$}

As illustrated by the example repeated in (17), the intensional reading is restricted to a positive value change, parallel to steigen $_{\text {fict }}$ and steigen $_{\text {dir }}$.

(17) Die Temperatur steigt von 3 auf 10 Grad / *von 10 auf 3 Grad.
the temperature rises from to degrees from to degrees
'The temperature is rising from 3 to 10 degrees/*from 10 to 3 degrees.'

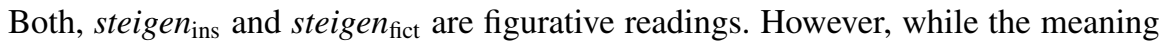
of steigen $_{\text {fict }}$ remains in the same source domain '(geometrical) space', steigen $_{\text {ins }}$ typically abstracts away into the domain denoted by the functional noun in subject position. Based on Gamerschlag et al. (2014) we assume the representation for steigen $_{\text {ins }}$ as in Die Temperatur steigt 'The temperature is rising' given in Fig. 10 below.

As can be seen, the frame of steigen $_{\text {fict }}$ is structurally nearly identical to the one of steigen $_{\text {dir }}$ except for the substitution of the POSITION-attribute by the TEMPERATUREattribute. As with steigen $_{\text {fict }}$, we consider this the result of an accommodation process triggered by a subject noun whose meaning is not compatible with one of the literal readings of the verb. However, as a contrast to steigen $_{\text {fict }}$, this accommodation process embeds the meaning of the subject noun in a different way: Since the dimension that comes with the functional noun can be considered as an abstract value space, it is the POSITION-attribute which is targeted by this process, such that the geometrical value space is replaced by the particular abstract value space. Again, we assume that the value change which takes place during the steigen-event is recorded as a trace defined in terms of values with a temporal ordering. This trace is an abstract object which can be understood as a path through the value space determined by the particular dimension expressed by the functional noun in subject position, such as TEMPERATURE or PRICE. As with steigen dir $_{\text {and }}$ steigen $n_{\text {fict }}$, a positive value change is assured by restricting the values of VERTICAL TRANSLATION as being (considerably) greater than zero, with the difference that the values are determined to being e.g. TEMPERATURE-values or PRICE-values by the functional noun. Note that our paths 
Fig. 10 Frame representation of Die temperatur steigt. 'The temperature is rising.'

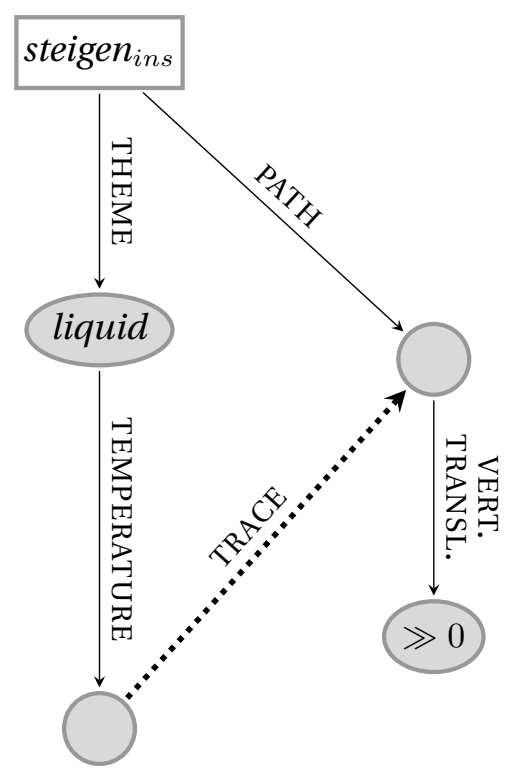

are paths in an abstract value space. Thus the attribute VERTICAL TRANSLATION is not restricted to a spatial vertical difference but rather is a more abstract function which operates on intervals on the scale in focus (e.g., the temperature scale).

Note that the representation above does not refer to a stative scenario/fictive change, as a contrast to steigen $_{\text {fict }}$. Rather, steigen $_{\text {ins }}$, although abstracting away from geometrical space, is represented as an "ordinary" change in time resulting in a truly dynamic expression just like the one expressed by the near-synonymous change of state verb (sich) erwärmen 'warm'.

\section{Conclusion}

In this paper, we have sketched how the fictive motion use of a verb such as German steigen 'climb, rise' can be systematically related to the dynamic readings of the verb by means of a frame analysis. Based on the observation that the intensional as well as the fictive motion use share with the directed motion reading the property that the value change expressed by the verb is restricted to a positive difference, we have argued that both figurative meanings are derived from the directed motion reading. Moreover, we have shown that both figurative uses trigger a different operation on the frame representation of the directional use: While the frame of the intensional use is derived from the one of the directional use by replacing the POSITION-attribute with the attribute that is specified by the subject noun, the fictive motion use is characterized by a deactivation of the dynamic components of the directed motion 
meaning due to the stationary character of the subject referent. In the latter case, the meaning of the subject is accommodated as an entity embedding the (fictive) path of motion. The adverbial modifiers attested for this reading were shown to specify a property of the path related to a value of an attribute of the theme, either via value sharing or via covariation.

Since we have focused on a single verb of motion in one particular language in this paper, two strands of further research naturally arise. First, it is necessary to discuss more motion verbs, especially those which do not have a literal directional use as opposed to the manner use or vice versa. Additionally, a detailed corpus study would allow for the investigation of a broader array of modifiers which could serve as a probe into the precise meaning of the fictive reading. A particularly promising topic is the interplay between scalarity, telicity and dynamicity. Given that scalarity is independent from telicity and dynamicity (Fleischhauer and Gamerschlag 2014), the question emerges whether dynamicity and telicity are related. Usually, telicity is understood as a change until a specific endpoint/a specific degree on a scale is reached (e.g. Hay et al. 1999). If this is an adequate notion of telicity, telicity presupposes dynamicity. However, some change of state verbs, including German steigen, exhibit fictive motion uses which allow for modifiers indicating telicity such as the time-span adverbial in kurzer Zeit 'within short time' in (18) below.

\section{Die Straße steigt in kurzer Zeit um 200 Meter} the road rises within short time by 200 meters ' The road rises by 200 meters within short time.'

The example above can be analyzed as spatially telic in the sense of Gawron (2009) and Champollion (2017) as an effect of adding the measure phrase um 200 Meter 'by 200 meters' whereas it can also be treated as 'conventionally' telic to some degree as indicated by the acceptability of the time-span adverbial in kurzer Zeit 'within short time'. One central question to pursue in relation to these two different types of telicity is which role the simulative component of the representation plays in regard to the admissibility of the time-span adverbial and its telicity effect.

Second, the availability and flexibility of the fictive use of verbs of motion differs significantly crosslinguistically. For example, as already shown by Matsumoto (1996) for Japanese, the set of verbs available for the fictive motion reading can be confined in various ways. In particular, only verbs which highlight some aspect of the path of motion allow for a fictive reading, while verbs denoting the manner of motion are ruled out from this use. This restriction follows directly from Japanese being classified as a verb-framed language in which manner verbs cannot combine with spatial modifiers such as directional PPs and measure phrases. It needs to be clarified how this generalization can be implemented into the frame account above, which is not sensitive to this typological parameter. One technical way of addressing this aspect might be to exclude the value of PATH from the list of externally specified arguments for this class of verbs. However, we will leave it as an open question whether the satellite-versus verb-framed language distinction calls for a deeper representational asymmetry in both language types. 
Acknowledgements The research presented in this paper was funded by the German Research Foundation (Deutsche Forschungsgemeinschaft) with a grant to the Collaborative Research Centre (SFB) 991 "The Structure of Representations in Language, Cognition, and Science". We are grateful to the two reviewers of this paper for many valuable comments. We would also like to thank the audiences of the CoSt 16 conference and the Annual Event Semantics Meeting in Cologne for their feedback on an earlier version. Thanks also to Curt Anderson for commenting on and proofreading the final version of this paper.

\section{References}

Barsalou, L. (1992). Frames, concepts, and conceptual fields. In A. Lehrer \& E. F. Kittay (Eds.), Frames, fields, and contrasts (pp. 21-74). Hillsdale NJ: Lawrence Erlbaum Associates Publishers.

Champollion, L. (2017). Parts of a whole: Distributivity as a bridge between aspect and measurement. Oxford: Oxford University Press.

Deo, A., Francez, I., \& Koontz-Garboden, A. (2013). From change to value difference in degree achievements. In Proceedings of SALT, Vol. 23, pp. 97-115.

Fillmore, Ch. (1982). Towards a descriptive framework for spatial deixis. In R. J. Jarvela \& W. Klein (Eds.), Speech, place and action: studies in deixis and related topics (pp. 31-59). New York: John Wiley and Sons.

Fleischhauer, J., \& Gamerschlag, T. (2014). We're going through changes: How change of state verbs and arguments combine in scale composition. Lingua, 141, 30-47.

Gamerschlag, T., Geuder, W., \& Petersen, W. (2014). Glück auf der Steiger kommt-A frame account of extensional and intensional 'steigen'. In D. Gerland, Ch. Horn, A. Latrouite, \& A. Ortmann (Eds.), Meaning and grammar of nouns and verbs (pp. 115-144). Düsseldorf: Düsseldorf University Press.

Gawron, M. (2009). The lexical semantics of extent verbs. Ms., San Diego State University.

Geuder, W., \& Weisgerber, M. (2008). Manner of movement and the conceptualization of force. Talk presented at the workshop Il y a manière et manière. Université d'Artois, Arras, France. http://semanticsarchive.net/Archive/Tk5YmEwN/MannerMovement_slidescompact.pdf.

Gibson, J. J. (1977). The theory of affordances. In R. Shaw \& J. Bransford (Eds.), Perceiving, Acting and Knowing (pp. 67-82). Hillsdale, USA: Lawrence Erlbaum

Gibson, J. J. (1979). The ecological approach to visual perception. New Jersey, USA, Lawrence Erlbaum Associates

Hay, J., Kennedy, Ch.,\& Levin, B. (1999). Scalar structure underlies telicity in 'degree achievements'. In T. Matthews \& D. Strolovitch (Eds.), Semantics and Linguistic Theory (SALT) IX (pp. 127-144).

Hütte, St, \& Matlock, T. (2016). Figurative language processing: Fictive motion and the visual world. In P. Knoeferle, P. Pyykkönen-Klauck, \& M. W. Crocker (Eds.), Visually situated language comprehension (pp. 185-203). Amsterdam: Benjamins.

Jackendoff, R. (1985). Multiple subcategorization and the theta-criterion: The case of 'climb'. Natural Language Linguistic Theory, 3, 271-295.

Kaptelinin, V. (2013). Affordances. The encyclopedia of human-computer interaction, 2nd Ed. https://www.interaction-design.org/literature/book/the-encyclopedia-of-human-computer-intera ction-2nd-ed/affordances.

Koontz-Garboden, A. (2010). The lexical semantics of derived statives. Linguistics and Philosophy, 33, 285-324.

Kövecses, Z. (2015). Where metaphors come from: Reconsidering context in metaphor. Oxford: Oxford University Press.

Langacker, R. W. (1986). Abstract motion. In Proceedings of the Twelfth Annual Meeting of the Berkeley Linguistics Society, pp. 445-471. 
Löbner, S. (1979). Intensionale Verben und Funktionalbegriffe. Tübingen: Narr.

Löbner, S. (1981). Intensional verbs and functional concepts: More on the "rising temperature" problem. Linguistic Inquiry, 12(3), 471-477.

Löbner, S. (2011). Concept types and determination. Journal of Semantics, 28(3), 279-333.

Löbner, S. (2017). Frame theory with first-order comparators: Modeling the lexical meaning of punctual verbs of change with frames. In H. H. Hansen, S. E. Murray, M. Sadrzadeh \& H. Zeevat (Eds.), Selected papers of the 11th International Tbilisi Symposium on Logic, Language, and Computation. LNCS, Vol. 10148, (pp. 98-117). Berlin: Springer.

Montague, R. (1973). The proper treatment of quantification in ordinary English. In Hintikka, J., Moravcsik, J. \& Suppes, P. (Eds.), Approaches to natural language. In Proceedings of the 1970 Stanford Workshop on Grammar and Semantics (pp. 221-242). Dordrecht: Reidel.

Matlock T (2004a) The conceptual motivation of fictive motion. In G. Radden \& R. Dirven (Eds.), Motivation in grammar (pp. 221-248). Amsterdam: John Benjamins.

Matlock, T. (2004b). Fictive motion as cognitive simulation. Memory and Cognition, 32, 1389-1400.

Matlock, T., \& Bergmann, T. (2014). Fictive motion. In E. Dąbrowska \& D. Divjak (Eds.), Handbook of cognitive linguistics (pp. 771-790). Berlin: DeGruyter Mouton.

Matsumoto, Y. (1996). Subjective motion and English and Japanese verbs. Cognitive Linguistics, $7(2), 183-226$.

Naumann, R. (2013). Outline of a dynamic theory of frames. In G. Bezhanishvili, S. Löbner, V. Marra \& F. Richter (Eds.), Logic, language, and computation. LNCS, Vol. 7758 (pp. 115-137). Berlin, Heidelberg: Springer.

Petersen, W. (2007). Decomposing concepts with frames. Baltic International Yearbook of Cognition, Logic and Communication 2 (pp. 151-170). Reprint 2015. In T. Gamerschlag, D. Gerland, R. Osswald \& W. Petersen (Eds.), Meaning, frames, and conceptual representation (pp. 43-67). Düsseldorf: Düsseldorf University Press.

Talmy, L. (2000). Toward a Cognitive Semantics, Vol. I. Concept structuring systems. Cambridge (Mass.): MIT Press.

Open Access This chapter is licensed under the terms of the Creative Commons Attribution 4.0 International License (http://creativecommons.org/licenses/by/4.0/), which permits use, sharing, adaptation, distribution and reproduction in any medium or format, as long as you give appropriate credit to the original author(s) and the source, provide a link to the Creative Commons license and indicate if changes were made.

The images or other third party material in this chapter are included in the chapter's Creative Commons license, unless indicated otherwise in a credit line to the material. If material is not included in the chapter's Creative Commons license and your intended use is not permitted by statutory regulation or exceeds the permitted use, you will need to obtain permission directly from the copyright holder.

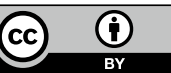

